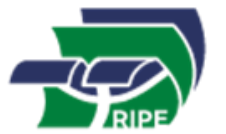

\title{
Estudo na Implementação de Eficiência Energética em Estabelecimentos Assistenciais de Saúde
}

\author{
Felipe Barbosa Nascimento ${ }^{1}$, Paulo Wallison Andrade Leite ${ }^{1}$, Marcel Veloso Campos ${ }^{2}$
}

1-Acadêmicos do Curso de Graduação em Engenharia Biomédica das Faculdades Unidas do Norte e

$$
\text { Minas - FUNORTE. }
$$

2-Professor Doutor das Faculdades Unidas do Norte de Minas - FUNORTE.

\section{RESUMO}

O consumo e gerenciamento da energia nos Estabelecimentos Assistências de Saúde (EAS) estão intimamente ligados à sustentabilidade financeira e ao crescimento eficiente de tais instituições. 0 conceito de eficiência energética se tornou tendência e de suma importância, uma vez que a crise hídrica e energética alcançou patamares cada vez piores e financeiramente altos, tais questões têm levado a pensar no uso cada vez mais eficiente de tal recurso, porém sem o detrimento do consumidor final, no caso o paciente. Contudo, a energia elétrica se tornou vital em qualquer seguimento, nos estabelecimentos alvo desse estudo ela é ainda mais importante, pois está ligada ao bom funcionamento das tecnologias em saúde. Além disso, consome uma parte considerável do orçamento desses estabelecimentos. 0 emprego das medidas de eficiência energética propostas no estudo tornará o funcionamento sustentável e trará não só retorno financeiro, mas também adequara à instituição há um crescimento saudável. 0 estudo em questão mostra o direcionamento de pontos aos quais sejam essenciais para fazer o uso eficiente da energia elétrica, tendo como premissa a verificação do real consumo do parque elétrico em relação à demanda contratada junto à concessionária de energia, munido dessas informações foi possível à elaboração de estratégias eficientes, adequação de consumos, ajuste de demanda e aplicação de métodos para conscientização e racionalização, pois é controlando as variáveis dentro da instituição e demostrando a eficiência dos procedimentos propostos, bem como a sua aplicabilidade, que se tornou possível gerar redução no custo com energia elétrica e assim diminuir o impacto financeiro, além de não comprometer a produção e o bem estar dos usuários, impactando apenas no fator econômico. A economia financeira conseqüente da aplicação deste estudo superou $16 \%$ do montante faturado em toda unidade hospitalar.

Palavras-chave: Energia elétrica. Sustentabilidade. Eficiência energética. Tecnologias em saúde.

\begin{abstract}
Consumption and energy management in Health Care Facilities (EAS) are closely linked to financial sustainability and the efficient growth of such institutions. The concept of energy efficiency has become a trend and of paramount importance, as the water and energy crisis has reached increasingly worse and financially high levels; such issues have led to the increasingly efficient use of such a resource, but without detriment of the final consumer, in this case the patient. However, electric energy has become vital in any company, in the EAS of this study, it is even more important, since it is linked to the good functioning of health technologies. In addition, it consumes a considerable part of the budget of these installations. The use of the energy efficiency measures proposed in the study will make the operation sustainable and will not only bring financial returns, but also fit the institution for healthy growth. The study in question shows the direction of points that are essential to make efficient use of electric energy, based on the
\end{abstract}


verification of the real consumption of the facilities in relation to the demand contracted with the energy concessionaire, provided this information was possible to elaboration of efficient strategies, adequacy of consumption, adjustment of demand and application of methods to raise awareness and rationalization of consumption, since it is controlling the variables within the institution and demonstrating the efficiency of the proposed procedures, as well as their applicability, which has become possible to generate reduction in the cost of electricity and thus reduce the financial impact, besides not compromising the production and the well-being of users, impacting only the economic factor. The financial savings resulting from the application of this study exceeded $16 \%$ of the amount billed in every hospital unit

Keywords: Electricity. Sustainability. Energy efficiency. Health Technologies

\section{Introdução}

O uso da energia se tornou essencial aos programas de eficiência em toda cadeia produtiva. Os estudos e atuações na área da qualidade e consumo de energia elétrica em Estabelecimentos Assistenciais de Saúde (EAS) tem sido proeminente nas últimas décadas, principalmente a partir da instituição de políticas de âmbito nacional e da tendência destas políticas a novas práticas de consumo eficiente da energia elétrica. Para efetivação destas novas práticas sem comprometer o conforto propiciado atualmente às pessoas pela energia elétrica (HADDAD, 2005).

Segundo Croucher (2011), a eficiência energética é alcançada pela analogia entre a demanda energética e o consumo efetivo, enquanto a conservação energética é alcançada pela diminuição de bens e serviços que consomem energia sem está necessariamente realizando algum tipo de trabalho. Para o Ministério das Minas e Energia, o alcance da eficiência energética resulta no uso da energia, sem detrimento da atividade executada, podendo ser realizada pela utilização de equipamentos mais eficientes ou pelo uso racional, ou ainda pela mudança de uma fonte energética (BRASIL, 2007).

Na esfera das tecnologias, a energia elétrica exerce atividade primordial, em razão da inexistência de substitutos. Na sua maioria, a mudança de rotina de trabalho e conscientização no consumo elétrico é fator de grande impacto no controle das faturas deste consumo e contemplam métodos eficientes para escolha adequada do contrato de suprimento energético. A aplicação de métodos isoladamente, que sejam arremetidos para a eficiência energética, determina de forma geral menor impacto econômico (BATISTA; FLAUZINO, 2012)

A otimização energética pode ser alcançada com dois tipos de condutas: técnicas ao qual envolvam os colaboradores e mudanças de hábitos de consumo, e as administrativas, através de estratégias inteligentes e tomadas de decisões na contratação do fornecimento de energia elétrica somado ao controle das faturas (OURESTE; FLAUZINO, 2012).

A procura pelo equilíbrio sustentável é objeto de aprimoramento e melhoria em várias instituições, tal situação se torna alcançável quando se pode equilibrar o desenvolvimento financeiro com atividades de conservação energética, sem comprometer a assistência e o conforto prestados aos clientes. 
Com os estabelecimentos assistenciais de saúde é primordial tal equilíbrio, uma vez que a busca desse dever com pequenos investimentos e mudanças nos hábitos, será possível apresentar indicadores favoráveis ao retorno financeiro a curto e médio prazo sem comprometer a qualidade do atendimento aos usuários, tornando assim o ambiente mais saudável por meio de instalações mais eficientes (CICONE et al. 2007).

O uso ineficiente da energia elétrica, não só aumenta o preço da energia, como também reduz a competitividade no setor. É sabido que, para obter eficiência e reduzir o consumo energético, é preciso uma visão integrada, tanto da oferta quanto da demanda energética dos diversos agentes envolvidos, sejam eles no âmbito governamental ou social (PINTO, 2004).

A maior classe de geração de energia elétrica do Brasil é originária das usinas hidrelétricas (FRANCISCO, 2009), essa classe apesar de ser proveniente de recursos renováveis depende do uso de um bem finito, tornando assim a redução do consumo desse recurso algo importante para o equilíbrio natural, isso se torna ainda mais importante, principalmente pela grande escassez de água causada pela estiagem prolongada acometida no Brasil.

O despertar de novas práticas políticas que cultuam a busca pela eficiência energética em estabelecimentos assistenciais de saúde surgiram, inicialmente, a partir do momento em que se observou que as demandas dos serviços prestados por estes estabelecimentos aumentaram consideravelmente na última década e a evolução tecnológica na assistência a saúde tem contribuído ao seu alto consumo energético. Essas políticas demonstraram a importância e a viabilidade econômica de ações de uso inteligente e de consumo eficiente da energia elétrica dos equipamentos eletromédicos (MENKES, 2004).

Estudos revelam que as instituições de saúde têm adotado projetos de eficiência energética a fim de gozar dos benefícios econômicos e sócio-ambientais, entretanto elas vão de encontro a duas dificuldades iniciais: análise e identificação correta dos recursos necessários para aprimorar a eficiência energética e a avaliação do risco eminente que circunda os investimentos essenciais (ARAGON; PAMPLONA; MEDINA, 2013).

Este trabalho apresenta a implantação de práticas de consumo eficiente da energia elétrica em um estabelecimento assistencial de saúde na cidade de Montes Claros e visa aferir pontos onde se possa aplicar e orientar melhorias nas instalações elétricas, garantindo a sua qualidade e continuidade, através da análise do parque elétrico da instituição e condições gerais das instalações, relacionando o uso da energia e desta forma verificar se os níveis de consumo estão acima da demanda contratada.

As metodologias aplicadas no programa de eficiência energética e a busca pela redução do consumo de energia não utiliza como base somente valores financeiros observados na conta ao final de cada mês, mas sim em duas variáveis que as formam, sendo elas: quantidade de trabalho que pode ser definida como serviços realizados na instituição em um dado período do dia, e a quantidade de energia elétrica consumida na execução dessas atividades (VIANA, A. et al). 
0 trabalho em questão busca mostrar a importância da gestão energética nos estabelecimentos de assistência à saúde, que vem sendo realizados para o consumo eficaz, os benefícios da eficiência energética e o caminho para uma gestão eficiente, o que inclui a qualidade na assistência e a capacitação da equipe quanto ao uso eficiente da energia elétrica, por meio de educação em serviço e ações voltadas para redução do consumo energético, mantendo o mesmo desempenho inicial.

A lei de no 10.295, de 17 de outubro de 2001, denominada lei de eficiência energética, levou aproximadamente uma década para ser aprovada pelo congresso Nacional e sancionada pelo Presidente da República. Assim, tem-se a reprodução de seus seis artigos as premissas da legalização do projeto, posto que, a lei deputa ao poder executivo o privilégio de estabelecer níveis máximos de consumo especifico de energia dos equipamentos em geral fabricados e ou comercializados no Brasil. Os indicadores desses níveis de consumo atribuem à aplicação de métodos e conceitos que evidenciam a eficiência energética na utilização de equipamentos eletro médicos fabricados e regulamentados a partir desta lei, assim como da utilização de sistemas de iluminação que proporcionam alta eficiência e baixo consumo de energia.

\section{Referencial Teórico}

\section{Indicadores de Eficiência Energética}

Na perspectiva generalista da Lei de Eficiência Energética, ela se dá quando realiza de alguma forma um trabalho mantendo seu desempenho com um consumo menor de energia elétrica e uma eficiência maior ou equivalente, tendo o consumo atual como referência. Visando quantificar esta melhoria, se utiliza comumente indicadores de eficiência energética.

Dentre os mais usuais, pode-se destacar: análise de Demanda, Custo Médio de Energia (CM), Consumo Específico de Energia (CE) e Fator de Carga da instalação (FC).

\section{Fator de potência}

Nesse sentido, Viana et al. (2012), destaca que o fator de potência se comporta como a razão entre a energia ativa e a raiz quadrada da soma dos quadrados das energias ativa e reativa, consumidas num mesmo período de tempo. Desta forma, observa-se que a relação entre o consumo de energia cabido à Demanda Média, pelo consumo cabido à Demanda Máxima e expresso como o Fator de Carga do estabelecimento consumidor. Podendo este, ser expresso pela relação entre o consumo real de energia elétrica e o consumo que existiria caso a carga fosse utilizada durante todo período de um potencial constante e igual à demanda máxima. 0 ideal é trabalhar com um Fator de Carga mais perto possível do estabelecimento. A Resolução da ANEEL no 414/2010, fixa o fator de potência de referência (FR), indutivo 
ou capacitivo, em 0,92, como limite mínimo permitido para as instalações elétricas dos estabelecimentos consumidores.

\section{Análise de Demanda}

De acordo com o Decreto 5.163/2004, a relevância em estabelecer valores apropriados de contrato de demanda, está em dois pontos importantes na legislatura:

- Quando a demanda consumida é menor que à contratada faturasse a demanda contratada;

- Caso a demanda consumida ultrapasse à contratada em alíquota superior ao percentual previamente estabelecido, serão aplicadas tarifas de ultrapassagem.

A demanda supra ou subdimensionada gera aumento de custo que pode e deve ser evitado por estabelecimentos assistenciais de saúde. 0 recomendado é supervisionar e gerir o consumo de energia de maneira preventiva à ocorrência de algum procedimento inadequado, que possa alavancar a elevação súbita e desnecessária da demanda consumida.

\section{Horário de ponta (HP)}

Assim como informa a ANEEL na sua Resolução Normativa ANEEL no. 414/2010, o horário de ponta (HP) é composto por três horas diárias consecutivas definidas pela distribuidora, considerando a curva de carga de seu sistema elétrico, porém serão excluídos tais horas nos finais de semanas e feriados pré-definidos por leis federais, em média são 66 horas durante o mês, devido a tais peculiaridades a tarifa do faturamento e cobrada de forma diferenciada, sendo seu valor bem superior ao horário de fora de ponta (HFP).

\section{Horário Fora de Ponta (HFP)}

Na Resolução Normativa ANEEL nº. 414/2010 fica definido como horário fora de ponta (HFP) como as horas restantes às três horas consecutivas que compõem o horário de ponta, sendo acrescidas das horas de finais de semana e dos feriados definidos por leis federais. Nesse horário a tarifa comprada pelo consumo e inferior ao horário de ponta (HP).

\section{Análise de Opção Tarifária}

Segundo a Resolução Normativa ANEEL no. 414/2010, o esqueleto tarifário brasileiro atual apresenta várias tarifas de diversas modalidades. Assim sendo, conforme a característica de consumo da empresa que serão analisadas as vantagens e desvantagens em terno de maiores e menores custos com a energia. Não é de boa prática adotar regras definidas para essa escolha, é preciso elaborar uma pesquisa esmiuçada do consumo do parque elétrico em questão, pontuando as horas que demandam maior consumo elétrico durante o dia e as flutuações de consumo ao decorrer do ano. Portanto, quanto maior a tarifa, maiores serão as possiblidades de gerenciamento destas despesas com energia, possibilitando 
obter custos menores, desde que seja possível evitar ou diminuir o consumo energético nos horários de maiores valores.

De maneira geral, para determinar o melhor sistema de tarifação, é preciso considerar:

- Valores médios de consumo mensais e de demanda em cada um dos segmentos, ponta e fora de ponta;

- Valores médios que serão faturados mensalmente nos segmentos em questão;

- Valores de demanda e consumo respectivamente, para tarifação convencional;

- Valores de ultrapassagem que possam ocorrer;

- Viabilidade de deslocamento do horário de ponta de trabalho de diversos equipamentos para tornar mínimo este consumo neste horário.

A análise tarifária se apresenta com um princípio de eficiência energética e potencialmente possibilita a diminuição do custo médio da energia, da mesma maneira que a otimização da demanda contratada e a relação do fator de potência elimina ociosidades ou ultrapassagens no sistema. Ações de gerenciamento energético como a substituição do suprimento no horário de ponta, bem como ações de substituição tecnológica mais eficiente, muitas vezes dependerão dos resultados obtidos com a implantação da eficiência energética no estabelecimento.

\section{Procedimentos Metodológicos}

\subsection{Objeto de Estudo}

Avaliar a efetividade da eficiência energética, encontrar e controlar variáveis de consumo dentro da instituição, gerando indicadores que demonstre a eficiência dos métodos propostos e a aplicabilidade de seus conceitos em um estabelecimento assistencial de saúde na cidade de Montes Claros - MG.

\subsection{Procedimentos de Coleta de Dados}

Durante a coleta de dados se utilizou de formulários para cadastro do parque tecnológico e etiqueta para identificação dos equipamentos cadastrados, somente com o nome do equipamento, modelo, horas e frequência de funcionamento. A utilização dos EPIs foi respeitada conforme rege as normas vigentes para o setor estudado e as informações obtidas foram transferidas para uma planilha, conforme expressa no desenvolvimento do trabalho.

\subsection{Procedimentos de Análise de Dados}

O projeto foi apresentado a um Estabelecimento Assistencial de Saúde em Montes Claros para as devidas autorizações e realização da pesquisa.

Os dados levantados dos equipamentos no setor, tais como, nome do equipamento, modelo, tensão nominal, corrente e potência, observadas no próprio equipamento, após analise das horas de funcionamento e frequência do uso mensal. Munidos dos dados descritos, foi possível elaborar planilha 
eletrônica para diagnostico, proposta dos principais pontos de intervenção e providencias relacionada ao projeto.

Os equipamentos cadastrados foram identificados, para evitar que o mesmo equipamento seja cadastrado duas ou mais vezes.

Em segundo momento, verificaram-se os 12 últimos faturamentos da conta de energia, sendo observado o consumo total em $\mathrm{kWh}$, que é o produto do consumo descrito pela potência pelo período de operação expresso em horas. Assim, foi verificada a média do consumo durante esse período, para que pudesse encontrar um valor ao qual se ajusta melhor ao consumo aferido e adequar à contratação da demanda ideal.

\section{Resultados}

Os estudos evidenciaram que as medidas tomadas foram de grande importância para a redução do consumo de energia e consequentemente a redução do faturamento financeiro gasto para tal fim.

Partindo das premissas que os valores tributados são diferentes em relação a certas horas do dia, e seguindo umas das medidas propostas para a execução do projeto que é o deslocamento do funcionamento dos vilões do consumo energético, essa ação impactou de forma positiva na redução do consumo de energia, uma vez que no período em que se mantiveram desligadas, no horário de ponta, foram reduzidos os valores médios de consumo, valores esses que no citado horário (HP) o preço médio do kW é três vezes superior em relação ao horário comum (HFP). Desta forma, houve a economia de 9,23\% do montante faturado em toda unidade hospitalar, somente com a implementação desta ação.

E em um outro momento, após análise do período de 12 meses da demanda contrata junto a concessionária de energia, ficou evidente que tal demanda excedia em torno de 35,5\% da demanda média consumida, após sugerir a adequação e redução dessa demanda de 450 para $330 \mathrm{~kW}$, houve a economia no faturamento final de cerca de 7,2 \%, uma vez que não ultrapassou o valor contratado. Tais ações combinadas geraram para a instituição uma economia entorno de 16,23 \% no final do faturamento mensal

Para eficácia do cálculo de demanda ideal, foi respeitada a margem de segurança de $26 \%$ superior ao valor médio do período analisado (PROCEL,2001).

\section{Discussões}

A concepção de carga instalada é o somatório das potências de todo o parque elétrico, que permaneçam em atividade e estejam instalados nas dependências do EAS, expressa em kWh (quilowatts $\mathrm{x}$ hora). Desta forma, no EAS, os maiores vilãos no elevado consumo elétrico são os sistemas biomédicos e sistema de iluminação. A solução técnica estabelecida para o projeto em questão aponta para economia e uso eficiente da energia elétrica. Como exemplo, aperfeiçoamento em sistemas de iluminação, ajustes de horários de atividade e troca de sistemas ineficientes eletricamente. 
No caso do EAS, o consumo energético se restringe praticamente ao consumo dos equipamentos médicos e sistemas de ar condicionado. Na tabela 1 está expressa a carga instalada na unidade estando classificado por perfil de equipamentos. E logo abaixo o percentual de consumo de cada equipamento (Quadro 1)

Quadro 1 - Carga Instalada na CME.

\begin{tabular}{|l|l|}
\hline Potência instalada CME (kW) & \\
\hline Autoclave & 10,70 \\
\hline Osmose & 1,50 \\
\hline Computadores & 1,50 \\
\hline Iluminação & 0,40 \\
\hline Ar condicionado & 8,77 \\
\hline Outros & 1,29 \\
\hline
\end{tabular}

Figura 1 - Relação de consumo na HP e HPF.

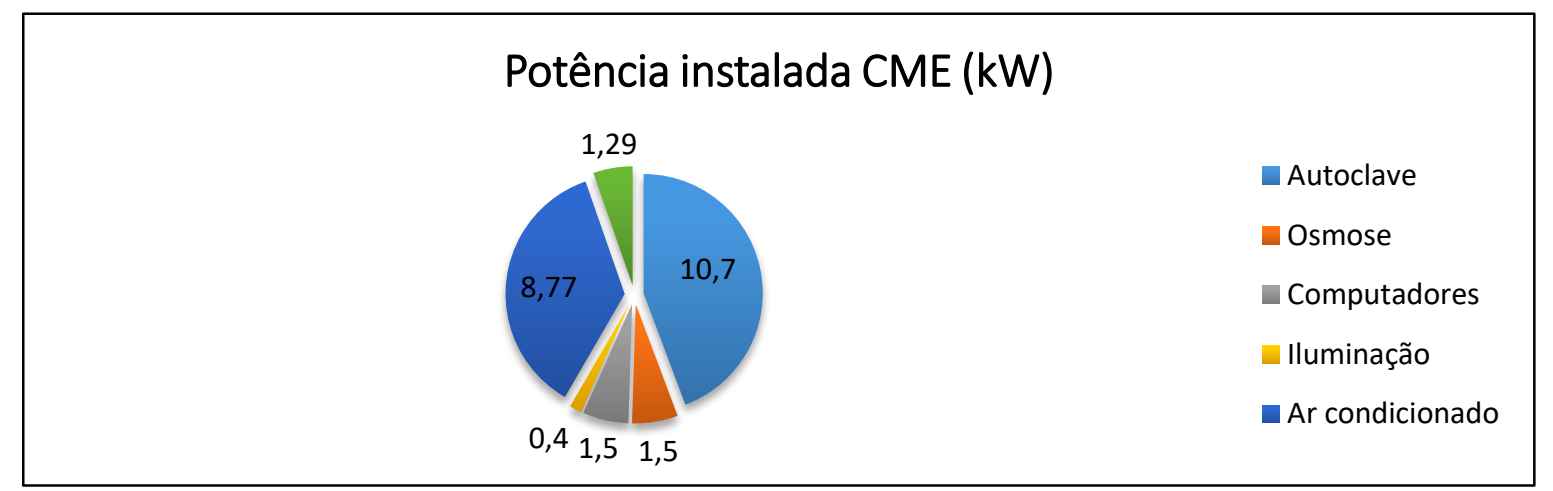

\section{Colaboração dos equipamentos biomédicos no consumo elétrico}

Dimensionado a carga, foi realizada a fragmentação da porção que cada equipamento expressa em relação ao consumo energético mensal. Desta maneira, tornou-se possível a percepção dos pontos mais significativos do processo, no qual obrigatoriamente deverão ser trabalhados para alcance da atenuação no consumo elétrico da unidade.

$\mathrm{Na}$ tabela 2 é apresentado o consumo mensal de energia elétrica da CME, com os referidos equipamentos destacados por porção de consumo energético mensal. E abaixo esta evidenciado o consumo nos horários de ponta (HP) e fora de ponta (HFP) destacados em um período de um ano (figura 2). 
Quadro 2 - Consumo energético mensal da CME.

\begin{tabular}{|l|l|}
\hline Porção de consumo energético mensal (kWh/mês) & 2568 \\
\hline Autoclave & 360 \\
\hline Osmose & 574,12 \\
\hline Computadores & 1089,6 \\
\hline Iluminação & 10696,74 \\
\hline Ar condicionado & $\mathbf{7 3 , 8}$ \\
\hline Outros & $\mathbf{1 5 3 6 2 , 2 6}$ \\
\hline TOTAL:
\end{tabular}

Figura 2 - Relação de consumo elétrico no horário de ponta e fora ponta

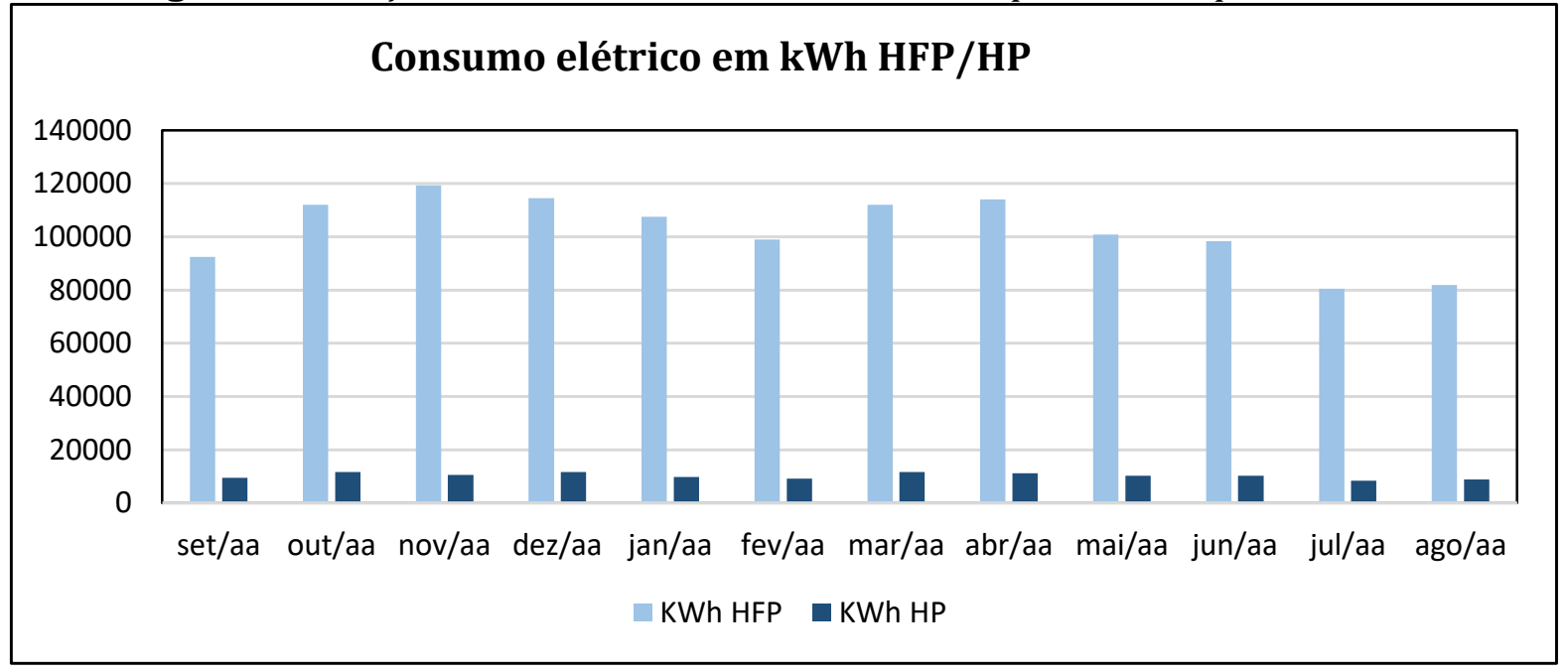

\section{Diagnóstico energético}

Um diagnóstico energético de uma unidade ou certa instalação atribui essencial importância ao diagnóstico de consumo visto que, qualquer método de gestão em eficiência energética terá obrigatoriamente que iniciar pelo reconhecimento do cenário energético da instalação. 0 princípio é óbvio para coordenar e indispensável para perceber o objetivo da gestão.

O diagnóstico energético é decifrado como um retrato do seu comportamento de uma determinada área de uma instalação consumidora, por exemplo, no que se refere ao sistema de ar condicionado ou sistema de equipamentos médicos. Através dele, avaliam-se o consumo efetivo de energia, estabelecendo os fluxos mais importantes e identificando as áreas ou setores onde é emergencial na sua atuação, seguido dos pilares da eficiência energética e do ponto de vista econômico.

\section{Característica de empresa}

O suprimento energético deste estabelecimento é realizado pela Companhia Energética de Minas Gerais (CEMIG) e seu contrato de segmento de energia elétrica é do subgrupo A4 com $330 \mathrm{KW}$ de demanda e estrutura tarifária Horo-sazonal verde. 
Como já foi citado, por motivos de confidencialidade dos valores de consumo energético, as informações aqui descritas são simplesmente estimativas obtidas pelo diagnóstico do parque elétrico ativo analisado e o histórico de consumo da unidade expresso nas faturas. Atualmente a demanda contratada pela instituição é de $330 \mathrm{~kW}$ e a média consumida no mês de abril á junho foi 313,250 kWh (trezentos e treze quilos e duzentos e cinquenta watts hora) por mês.

\section{Estudo de Caso}

Foi estudada a viabilidade, em seguida aplicada capacitação para os colaboradores visando reduzir o consumo de energia elétrica no horário de ponta. Isto representou uma redução na produção e também do consumo elétrico pelo estabelecimento, sendo orientado aos colaboradores conciliar outras atividades no horário de ponta e retomar a produção no horário fora de ponta.

Este estabelecimento apontou nesse período de maio a agosto o gasto de $\mathrm{R} \$ 252.109,80$ (duzentos e cinquenta e dois mil, cento e nove reais e oitenta centavos). Inicialmente se fez necessária análise do contrato de energia da instituição com a CEMIG, ou seja, estudar as tarifas e posteriormente efetuar ajuste tarifário com a expectativa de conseguir alcançar economia no valor pago e transferir os custos com energia para outros segmentos, conforme demonstrando na figura 3, aonde pode ser observado que após a adequação contratual, a linha que expressa a demanda contratada se aproximou de forma acentuada do consumo real utilizado, uma vez que no período anterior a essa medida, a demanda contratada ficava muito superior ao consumo real. Com a possibilidade de redução dos gastos com energia elétrica, a instituição será capaz de investir em novas tecnologias objetivando um consumo menor de energia.

Figura 3 - Adequação contratual.

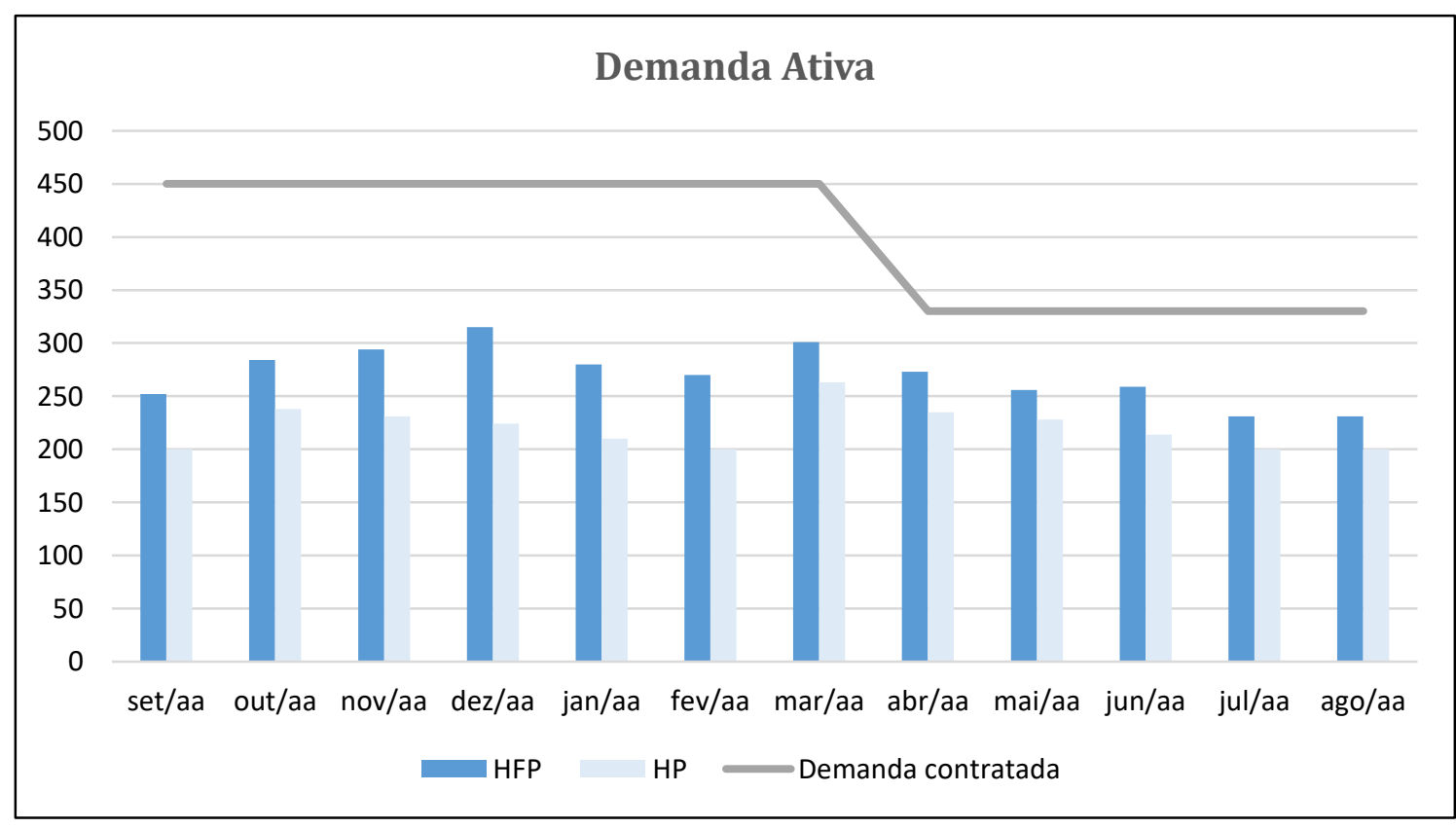


Primeiramente devem-se observar na tabela 3 os valores de energia ativa no horário de ponta. Os montantes dos valores apresentados correspondem respectivamente à redução dos valores a pagar do histórico de consumo da empresa. Na mesma tabela e apresentado cada tipo de modalidade de tarifação e sua respectiva tarifa disposta em cada mês. A conformidade da demanda e adequação dos horários de consumo possibilitou uma economia média de $\mathrm{R} \$ 10.000,00$, aproximadamente. Para conseguir essa economia não fez necessário investimento financeiro algum, somente o planejamento apropriado como demonstrado no quadro 3.

Quadro 3 - Levantamento dos valores faturados pela concessionária durante aplicação

\begin{tabular}{|l|l|l|l|l|l|l|l|l|l|}
\hline & $\begin{array}{l}\text { Energia } \\
\text { Ativa } \\
\text { kWh HP }\end{array}$ & Tarifa & $\begin{array}{l}\text { Energ } \\
\text { ia } \\
\text { Ativa } \\
\text { kWh } \\
\text { HFP }\end{array}$ & Tarifa & $\begin{array}{l}\text { Demanda } \\
\text { Ativa kW } \\
\text { HFP s/ICMS }\end{array}$ & Tarifa & $\begin{array}{l}\text { Demanda } \\
\text { Ativa } \mathbf{k W} \\
\text { HFP }\end{array}$ & Tarifa & Total \\
\hline mai & 10.150 & 1,7106 & 100.800 & 0,4509 & 74 & 9,6061 & 256 & 13,1023 & $68.422,06$ \\
\hline Jun & 10.150 & 1,7372 & 98.350 & 0,4601 & 71 & 9,6186 & 259 & 13,1112 & $68.333,19$ \\
\hline Jul & 8.400 & 1,7484 & 80.500 & 0,4656 & 99 & 9,5499 & 231 & 12,9669 & $57.478,65$ \\
\hline Ago & 8.750 & 1,7247 & 81.900 & 0,4592 & 99 & 9,4542 & 231 & 12,7912 & $57.875,90$ \\
\hline
\end{tabular}

\section{Viabilidade}

Após todos esses estudos com objetivo de reduzir o consumo de energia elétrica nos EAS e para utilização racional e eficiente dos dispositivos elétricos, foi realizada uma análise de ordem técnicoeconômica evidenciando quais opções são possíveis para a instituição investir e as que apresentam um retorno imediato.

O estudo da viabilidade técnico-econômica permitiu elaborar o melhor recurso técnico para reduzir o consumo, considerando a sua prestação econômica. A conjunção destes dois elementos, possibilita a elaboração de um projeto de investimento otimizado e realista para as verdadeiras necessidades do EAS, sendo apresentadas várias propostas, para melhor apreciação e decisão do departamento responsável pela unidade.

\section{Viabilidade do ponto de vista econômico e tempo de retorno financeiro}

\section{Adequação do horário de consumo}

A adequação do horário de funcionamento dos sistemas elétricos, como exemplo, autoclave e sistemas de ar condicionado sendo desligados no horário de ponta (HP) e somente religados no horário fora de ponta (HFP) é apresentada como a maior responsável pela economia energética desse estudo.

Assim, com descreve a ANEEL (Agência Nacional de Energia Elétrica) em relação ao horário de faturamento do consumo de energia elétrica, é definido situações distintas ao qual se tem o horário de 
ponta. Compreende às três horas consecutivas do dia que exigem a maior demanda de energia elétrica para consumo das concessionárias sendo das 17:00 as 20:00 horas, exceto aos sábados, domingos e feriados nacionais, definido pela CEMIG, em função das características de seu sistema elétrico. Nesse horário a demanda e o consumo de energia elétrica têm preços que representam valores três vezes superiores ao faturado no horário fora de ponta, compreendido pelas vinte e uma horas restantes do dia.

A grande ação foi adequação de horário, executando suspensão prioritária de funcionamento dos equipamentos de maior consumo no horário de maior tarifação (HP), de forma que essa rotina não tivesse impacto significativo na demanda do setor, aumentando a produção e remanejando o pessoal para outras áreas de produção, de forma suprir a necessidade produtiva de materiais para serem reprocessados após as 21:00 horas. Essa ação gerou a maior porcentagem de economia reduzindo o consumo mensal e consequentemente a redução no faturamento da instituição, disseminando esta ação para toda a empresa.

Partindo da definição que só se atinge a eficiência energética quando aperfeiçoar o consumo de energia elétrica, sem que haja prejuízo ao trabalho realizado anteriormente. Também se tem como um dos objetivos para alcançar ainda mais resultados efetivos e expressivos, a substituição das lâmpadas fluorescentes por lâmpadas LED's, mais eficientes energeticamente.

Por meio dos estudos prévios realizados no setor de esterilização, pode-se viabilizar a substituição com um pequeno investimento financeiro, podendo observar através da tabela 4 que obtém a redução de cerca de 50\% no faturamento relacionada à iluminação. Além do mais, as lâmpadas LED são superiores na quantidade de lumens emitidos, proporcionando aos usuários e colaboradores uma melhor iluminação e conforto visual, podemos ter também um menor gasto em relação à manutenção dos sistemas, pois sua vida útil supera entorno de cinco vezes a vida útil das lâmpadas fluorescentes.

Quadro 4 - Levantamento do custo para substituição do sistema de iluminação.

\begin{tabular}{|l|l|l|l|l|l|l|l|}
\hline Equipamento & $\begin{array}{l}\text { Preço } \\
\text { Estimado }\end{array}$ & Quant. & $\begin{array}{l}\text { Potência } \\
\text { (W) }\end{array}$ & $\begin{array}{l}\text { Horas/ } \\
\text { mês }\end{array}$ & Consumo & $\begin{array}{l}\text { Luminosidade } \\
\text { (Lumens) }\end{array}$ & $\begin{array}{l}\text { Vida } \\
\text { Útil (h) }\end{array}$ \\
\hline $\begin{array}{l}\text { Lâmpada } \\
\text { fluorescente }\end{array}$ & 5,89 & 36 & 20 & 1500 & 297,6 & 1000 & 10.000 \\
\hline $\begin{array}{l}\text { Lâmpada } \\
\text { fluorescente }\end{array}$ & 7,50 & 36 & 40 & 1860 & 792 & 1200 & 10.000 \\
\hline \begin{tabular}{l} 
Lâmpada de LED \\
\hline Lâmpada de LED
\end{tabular} & 20,00 & 36 & 18 & 1860 & 356,4 & 1800 & 50.000 \\
\hline
\end{tabular}

Pode-se concluir em análise previa da tabela 4 que com um investimento de $\mathrm{R} \$ 1.314,00$ empregados na substituição das lâmpadas do setor de esterilização, terá uma economia de 
aproximadamente $R \$ 554,65$ mensais no faturamento de energia, tal economia poderá recuperar o investimento inicial em menos de três meses após o investimento.

\section{Conclusões}

Após análise dos resultados obtidos, ficou evidenciado que, as ações tomadas foram de eficiência distinta, cada conduta colaborou de forma decisiva para alcançar o objetivo proposto no estudo.

A maior evidencia que poderia ser apresentada como fruto positivo desse trabalho ficou manifestado no faturamento dos meses subsequentes a aplicação das medidas de eficiência energética, pois houve uma economia entorno de $16,23 \%$ na fatura de energia elétrica.

Conclui-se que a eficiência energética pode ser alcançada, não somente com grandes investimentos financeiros, mas também com pequenos ajustes de funcionamento, o que deve primeiramente entender o ciclo de faturamento de cada concessionária, para enfim, adotar medidas no que se refere a cada ação dentro do nosso espaço de trabalho.

\section{Trabalhos futuros}

O estabelecimento alvo do estudo apresenta também no seu sistema de iluminação, lâmpadas fluorescentes compactas, que apesar de terem um bom rendimento custo benefício, ainda não é a melhor opção nos dias atuais. A sua substituição por lâmpadas LED’s, proporciona um importante investimento para a redução de custo, conforme descrito anteriormente. Desta forma, como trabalho futuro pretendese substituir o sistema de iluminação por equipamentos mais eficientes.

\section{Referências Bibliográficas}

HADDAD, J. A lei de eficiência energética e o estabelecimento de índices mínimos de eficiência energética para equipamentos no Brasil. Revista Brasileira de Energia, v. 11, n. 1, 2005.

CROUCHER, M. Potential problems and limitations of energy conservation and energy efficiency. Energy Policy, v 39, n 10, p. 5795-99. October, 2011.

BRASIL, Ministério das Minas e Energia - MME. Plano Nacional de Energia 2030. Eficiência Energética, Brasília, v. 11, n. 1, p13 -17, janeiro, 2007.

BATISTA, O. E.; FLAUZINO, R. A. Medidas de Gestão Energética de baixo custo como estratégia para redução de custos com energia elétrica. GEPROS. Gestão da Produção, Operações e Sistemas, Ano 7, no 4, out-dez/2012, p. 117-134.

OURESTE, E. B.; FLAUZINO, R. A. Gestão da Produção, Operações e Sistemas: Medidas de gestão energética de baixo custo com estratégia de redução de custo com energia elétrica. Revista Gespro, Ano 7, no 4, outdez, p. 117-134, 2012. 
CICONE, D. et al. Atratividade financeira e tomada de decisão em projetos de eficiência energética. Revista Brasileira de Energia, v. 13, n. 2, p. 129-46, 2007.

PINTO, M. S. L.; OLIVEIRA, R. R. Estratégias Competitivas no Setor Elétrico Brasileiro: Uma Analise Dos Interesses e Expectativas dos Atores da Chesf. Revista de Administração Contemporânea, Curitiba, v. 8, n. Spe, p. 131-55, 2004.

FRANCISCO, W. C. Energia Hidrelétrica. Disponível em: <http://Www.mundoeducacao.com.br/geografia/energia-hidreletrica.htm>. Acesso em: 16 de março de 2016.

MENKES, M. Eficiência Energética, Políticas Públicas e Sustentabilidade. Tese de Doutorado Universidade de Brasília, Brasília, 295 p., março, 2004.

ARAGON, C. S.; PAMPLONA, E; MEDINA, J. R. V. Identificação de investimentos em eficiência energética e sua avaliação de risco. Gestão Produção, São Carlos, v. 20, n. 3, p. 525-36, 2013.

VIANA, A. et alPROCEL. MANUAL DE TARIFAÇÃO DA ENERGIA ELÉTRICA. Disponível em:

<http://www.sef.sc.gov.br/sites/default/files/manual_de_tarifacao.pdf>, abr,2016.

VIANA, A. et al. EFICIÊNCIA ENERGÉTICA: FUNDAMENTOS E APLICAÇõES. Campinas - SP, v. 1, p. 31$32,2012$.

PROGRAMA DE EFICIENTIZAÇÃO ENERGETICA. Manuais ELEKTRO de Eficiência energética. Disponível em: <http://www.elektro.com.br/Media/Default/DocGalleries/Eficientiza\%C3\%A7\%C3\%A3o\%20Energ\% C3\%A9tica/novo_segmento_industrial_adm_energia-09-06-2014_dupla.pdf>, mar/ abr, 2016.

LEI № 10.295, DE 17 DE OUTUBRO DE 2001. Lei de Eficiência energética. Disponível em: <http://www.planalto.gov.br/ccivil 03/leis/LEIS 2001/L10295.htm> abril, 2016.

VIANA, A. N. C. et al. Eficiência Energética: Fundamentos E Aplicações. Campinas - SP: 1ํㅡ., 2012. $314 \mathrm{p}$.

DECRETO № 5.163 DE 30 DE JULHO DE 2004. Regras Gerais de Comercialização de Energia Elétrica. Disponível em: <www.planalto.gov.br/ccivil_03/_ato2004-2006/2004/decreto/d5163.HTM>, maio, 2016. 
PROCEL - Programa Nacional de Conservação de Energia Elétrica, Manual de Tarifação de Energia Elétrica, PROCEL - Programa Nacional de Conservação de Energia Elétrica, Primeira Edição, agosto, 2011.

RESOLUÇÃO NORMATIVA 414/2010: atualizada até a REN 499/2012 - ANEEL. Condições gerais de fornecimento de energia elétrica. Disponível em: <www.aneel.gov.br/biblioteca/Edicaolivros2012Resolucao414_2010.cfm>, maio, 2016. 